\title{
Intelligently programming of thin - walled robotic component for Industry 4.0
}

\author{
Peter Michalik ${ }^{1}$, Jozef Zajac ${ }^{1}$ Vieroslav Molnar ${ }^{1}$, Luboslav Straka ${ }^{1}$ \\ Peter Tirpak $^{2}$, Michal Petruš ${ }^{3}$, Martin Ambrozy ${ }^{4}$
}

Abstract. The article deals with the intelligent programming of the production of a thin-walled ALMg4,5Mn duralumin robotic component. Described is the Manual Guide i., which utilizes clear and simple programming working windows for workshop programming. This work-programming environment allows communication with the superior computer to meet the conditions of Indus-try 4.0. Thick-walled robotic component with a $2.5 \mathrm{~mm}$ wall thickness was milled using a 11X 203440 DIN 6535 HA TiAlN cutter with a diameter D of $12 \mathrm{~mm}$ at a depth of $7 \mathrm{~mm}$. The surface roughness of the milled surfaces was measured at 60 and $50 \mathrm{~mm}$ long by means of a Mitutoyo SJ 400 dredger.

Keywords: thin walled, shop - floor programming, Industry 4.0

\section{Introduction}

Like the revolutions that preceded it, the Fourth Industrial Revolution has the potential to raise world income levels and improve the quality of life of the world's citizens. New technologies and advances have brought major changes for many countries, in the last 30 years, the number of people living in poverty has dropped from $60 \%$ to $22 \%$ in India, while China suffered from the poverty of 600 million people in the same period [1]. To date, those who have gained the most access to the digital world have been the co-workers. Technology has enabled new products and services that increase efficiency and enjoyment of our personal lives. Ordering a taxi, booking flights, purchasing goods, making payments, listening to music, watching movies or playing games can usually be done remotely. In the future, these technological innovations will lead to miraculous changes in supply, with long-term gains in efficiency and productivity gains. The Industry 4.0 philosophy progressively penetrates into individual industrial areas. Its basic idea is closely related to the use of digital models, technologies, and the subsequent application of acquired knowledge. Because it is still a relatively new and not completely mapped concept, it is necessary to analyze, analyze, develop and explore the various aspects of the carrier. The aim of the project is to look more closely at the possibilities of digitization for Industry 4.0 needs in the areas of logistics and manufacturing technologies. Concretely, it will explore the possibilities of developing individual procedures for the creation of digital models [2],[3]. The focus will be on verifying the capabilities of individual software tools. In general, it is considered using tools that

\footnotetext{
1 Technical University of Košice, Department of Automotive and Manufacturing Technologies, Faculty of Manufacturing Technologies, Bayerova 1, 08000 Prešov, Slovak Republic, email: peter.michalik@tuke.sk

2 Ložin 177, 07205, Slovakia e-mail:tirpak@centrum.sk

3 Milpoš 177, 082 71, Slovakia, e-mail: Michal.petrus4@gmail.com

4 Levoča, Francisciho 33, 082 71, Slovakia, e-mail: martin.ambrozy@gmail.com
} 
can be integrated into the PLM system [4]. Vertical integration of intelligent manufacturing systems such as intelligent smart and intelligent products and interconnection, for example, of intelligent logistics, production and marketing and intelligent services with a strong focus on the needs, individual and specific customer options[5]. Horizontal integration through a new generation of global networks generating added value, including business partner integration and customer-centric, new business models, and cross-country and continent cooperation [6], [7]. European manufacturing plants provide a number of different processing possibilities for manufacturing a specific product. Different advantages and limitations may arise from each one of these processing possibilities that are function of both the geometry, material and the batch size of the part to be manufactured. However, one of the main driving forces in today's production is the environmental friendliness as well as the quick response to market demands through an efficient process planning approach. The status quo industry today can be summarized into the following:

$>$ Large unnecessary energy use in the industrial sector (20-50\%)

$>$ Highly demanding customers need short lifecycle products, increasing the need for flexible manufacturing processes

$>$ Increased needs for fast alternative process plans proposals, for the manufacturing of a specific product The ENEPLAN vision is the development of a MetaCAM tool that will optimize the process planning in terms of energy efficiency, environmental friendliness, and quick response to market needs, cost and flexibility. The projects key objectives can be summarized into the following:

$>$ Environmental footprint reduction for metal formed components by selecting a more energy efficient combination of process among those available in the already existing supply chain.

$>$ Energy efficiency improvement in working conditions

$>$ Multi-process, multi-company distributed control [8].

Roblek et al. focused in this article the importance and influence of Industry 4.0 and consequently the Internet-connected technologies for the creation of value added for organizations and society [9],[10]. The contribution of the article is mainly conceptual. With the development of the Internet, the Internet of things that is central to the new industrial revolution has led to "Industry 4.0." The aim of this article is to synthesize the known theory and practices of Industry 4.0, and to investigate the changes that will result from Industry 4.0 and with the development of the Internet of things [11]. Cao et al. studied, the formation and characteristics of CNC turret punch were analyzed, and the intelligent process programming system were researched, to make $\mathrm{CNC}$ turret punch press more intelligently, and promote the development of China's manufacturing industry [12],[13].

Wu researched Laser Metal Deposition Shaping (LMDS). During this process, a certain alloy is fused onto the surface of a substrate. Laser deposition devices, namely powder feeder. which is a state-of-the-art technologThe LMDS system consists of four primary components: energy supply module, motion control module, powder delivery module, and computer control module.y which correlates the Rapid Prototyping and Manufacturing (RP\&M) and laser processing [14]. 


\section{Machined material and manufacturing drawings.}

For machining, a blank stock of P12 x 62 x $52 \mathrm{~mm}$ was selected, $\mathrm{Al} \mathrm{Mg4.5 \textrm {Mn }}$ material containing alloying elements Tab. 1 with a strength of $310 \mathrm{MPa}$ and a modulus of elasticity of $130 \mathrm{MPa}$. Manufacturing drawings, we see in (Figure 1).

Table. 1 Chemical composition of the material AlMg4.5Mn

\begin{tabular}{|c|c|c|c|c|c|c|c|c|c|}
\hline Al & $\mathbf{M g}$ & $\mathbf{M n}$ & $\mathbf{S i}$ & $\mathbf{F e}$ & $\mathbf{C u}$ & $\mathbf{C r}$ & $\mathbf{Z n}$ & $\mathbf{T i}$ & Other \\
\hline 93.8 & 4,5 & 0,7 & 0,1 & 0,3 & 0,1 & 0,1 & 0,2 & 0,1 & 0,1 \\
\hline
\end{tabular}

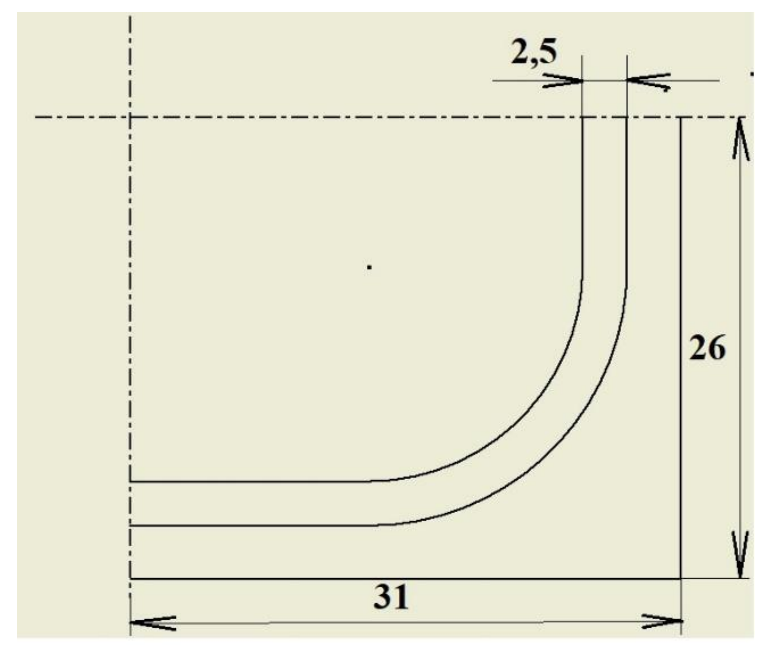

Figure 1. Manufacturing drawing of thin - walled robotic component

\section{Programming of component manufacturing.}

Shop - floor programming in the Manual Guide, you need to define the size of the stock in the second block of the program (Figure 2). This block is only required for the Simulation mode. 


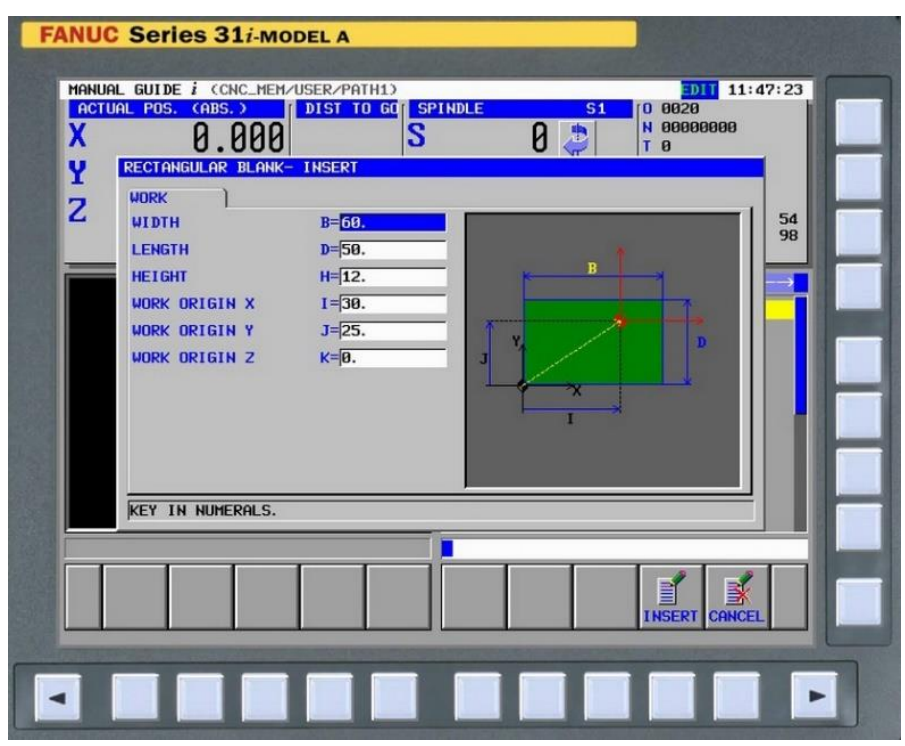

Figure 2. Selection of stock for simulation

After correctly defining the individual size of the blank in the rectangular working window, the Manual Guide generates the G1902 code and writes it directly into the editing window (Figure 3).

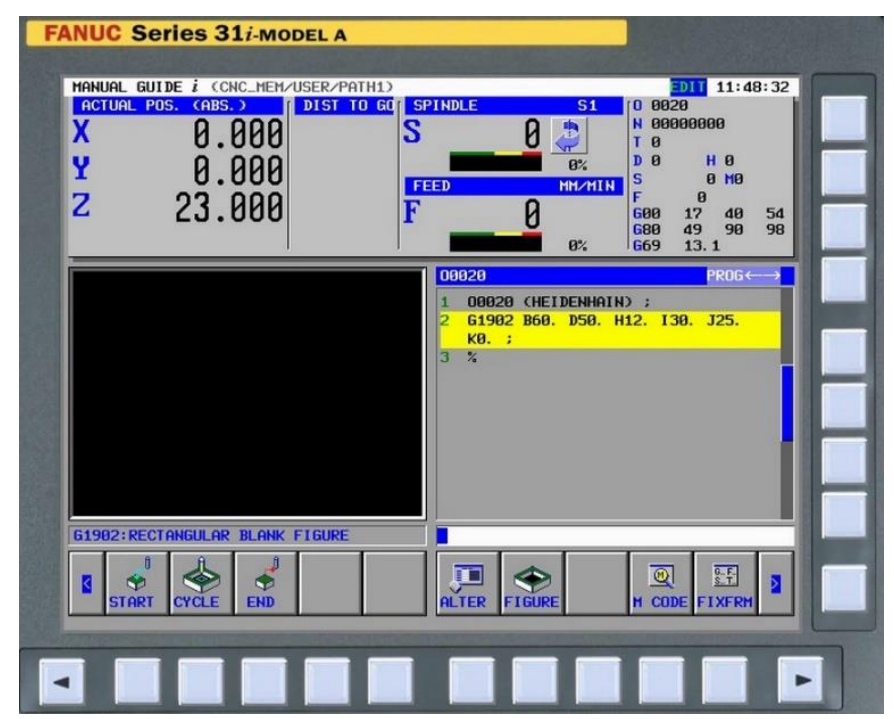

Figure 3 Generation G codes for definition of dimension stock 
Following selection and definition milling cycle for outer wall contouring (Figure 4). In cycle for outer wall, contouring is necessary definition depths and feeds (Figure 5).

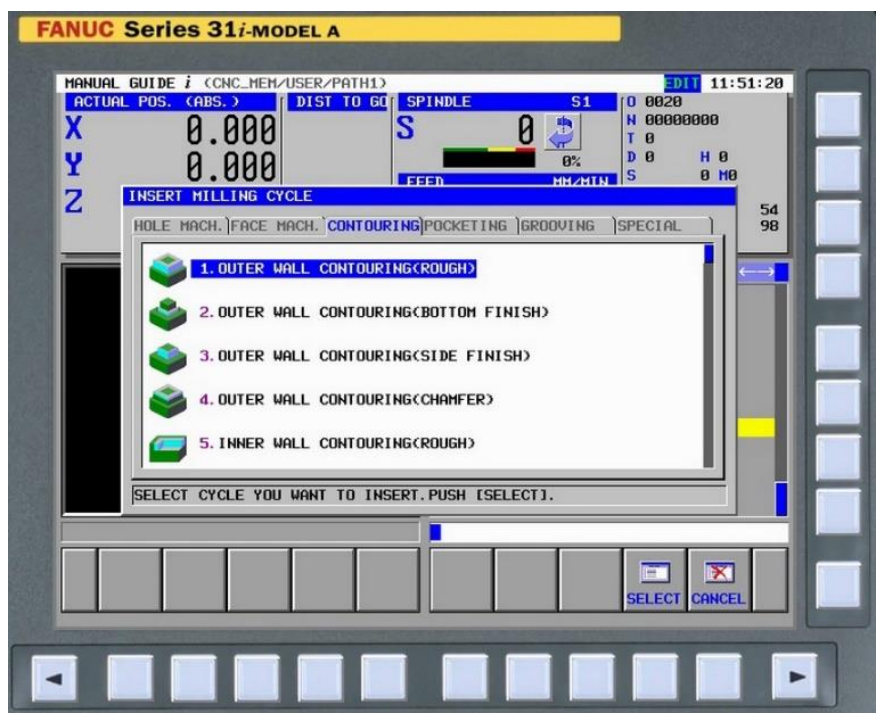

Figure 4. Selection insert milling cycle

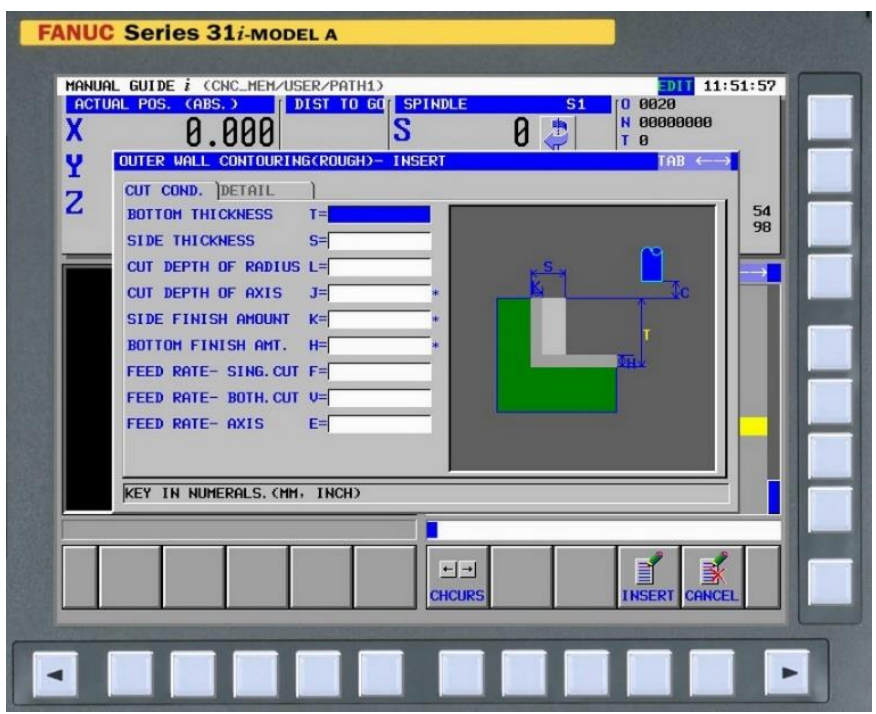

Figure 5. Definition parameters for outer wall, depths and feeds 
In the next step we define in window outer wall contouring approaches and escapes (Figure 6). After press button insert we can define values axis of center point (Figure 7).

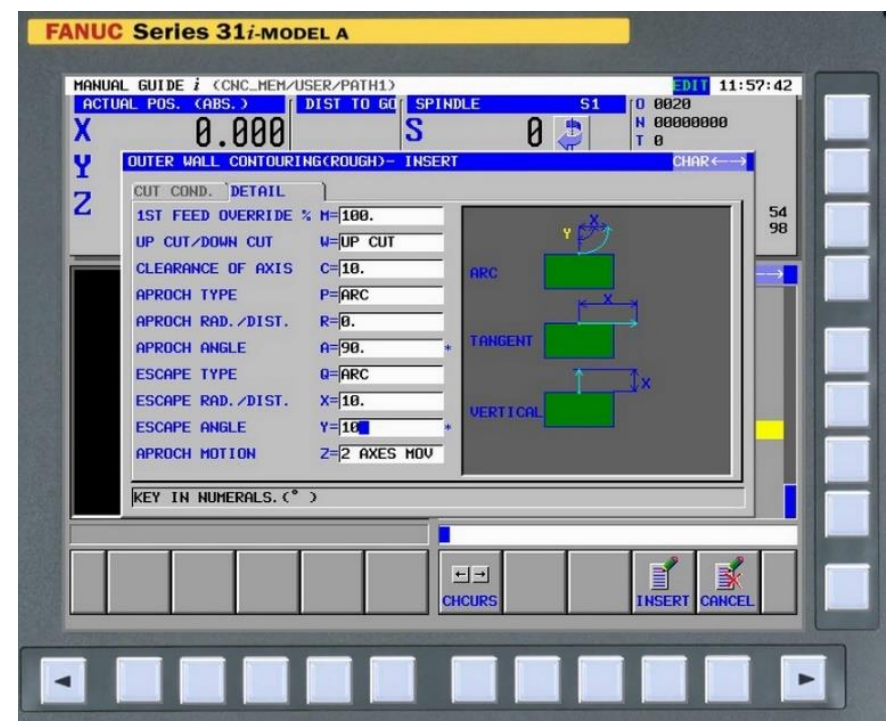

Figure 6. Definition approaches and type escapes for machining outer wall

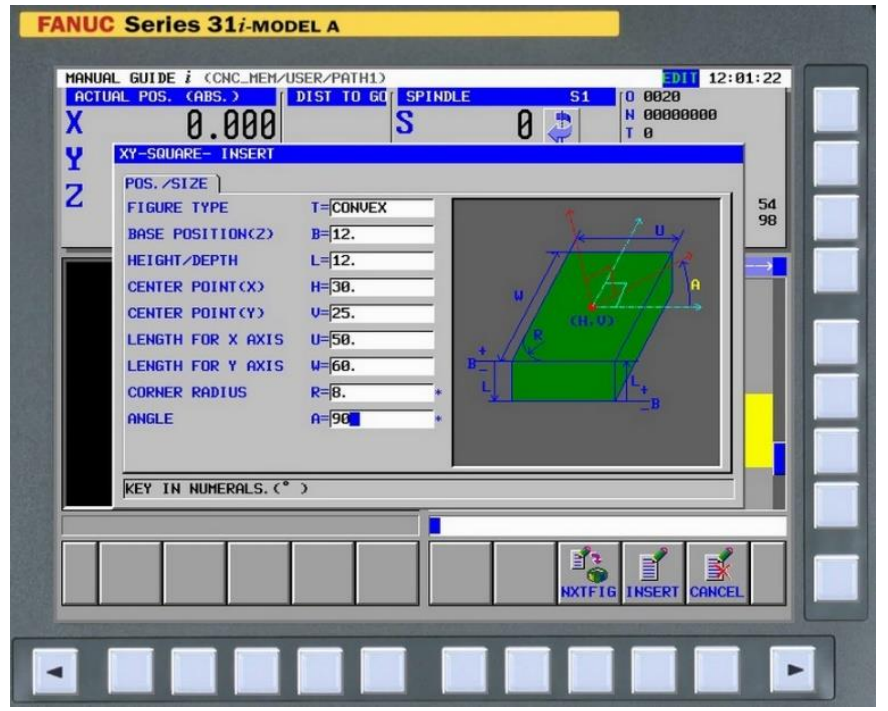

Figure 7. Definition values axis of center point 
Similar procedure is required or milling the inner pocket. In the last step we define tool (his shape and position axis of spindle) for simulation (Figure 8). Now it possible make simulation of production thin walled robotic component (Figure 9).

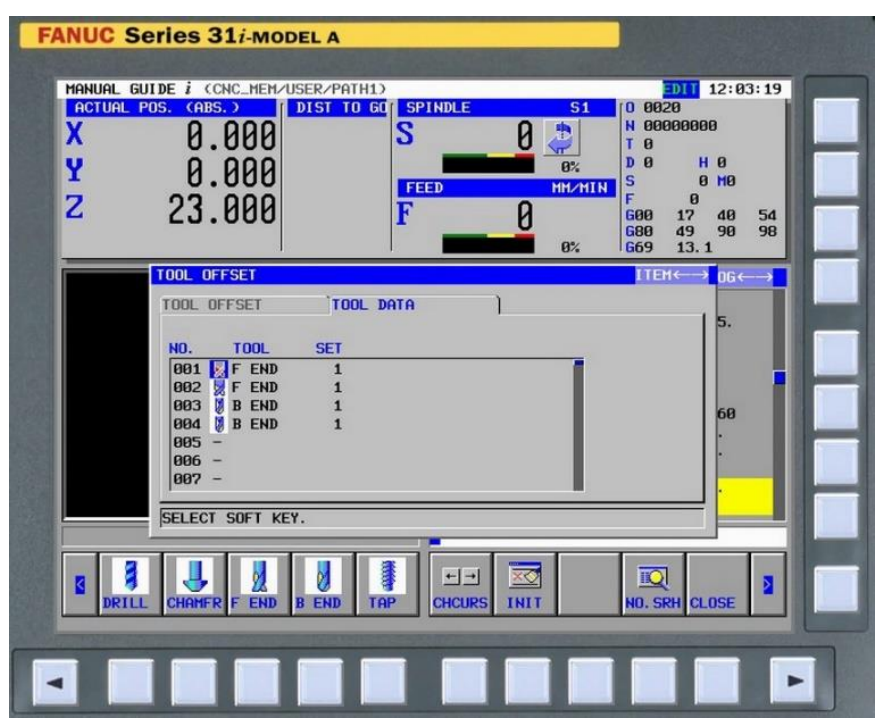

Figure 8. Selection of tool for simulation production

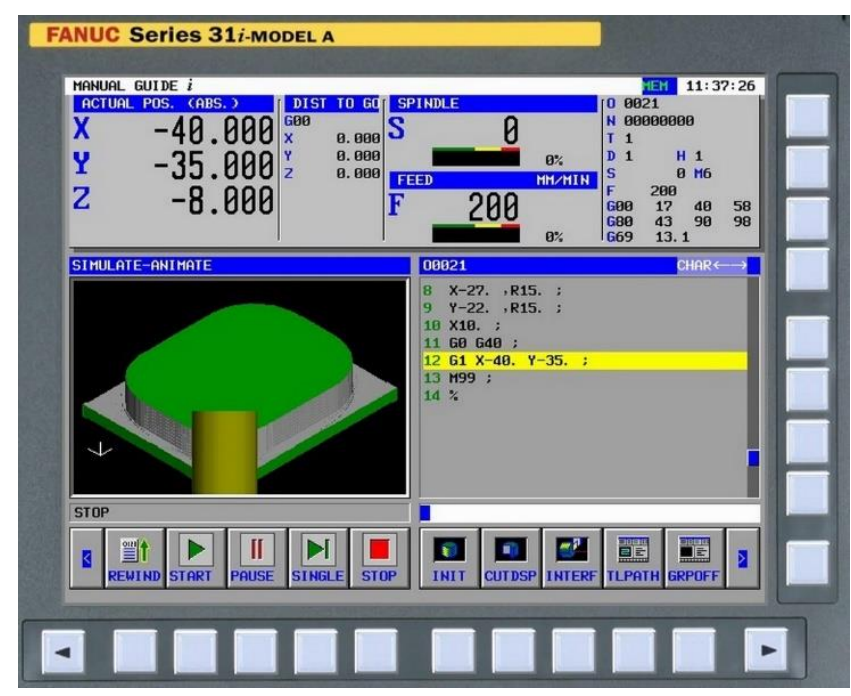

Figure 9. Simulation production of outer wall thin walled robotic component 
After repair our mistakes in simulation program we going to prepare mandrel and tool (Figure 10). Following adjusting X, Y and Z values for zero point of component (Figure 11).

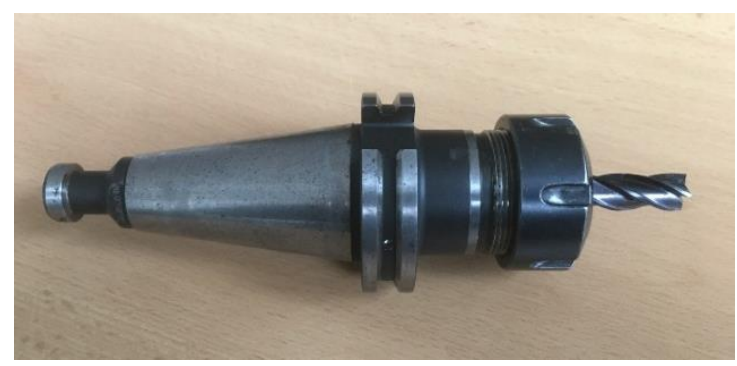

Figure 10. Ready mandrel and tool for milling

After selecting AUTO mode, you can milling outer wall (Figure 12) and inside pocket.

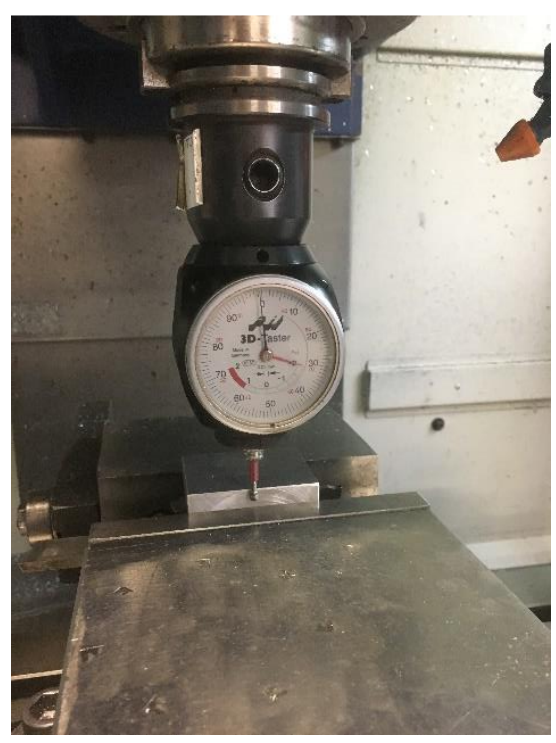

Figure 11. Adjusting of zero point

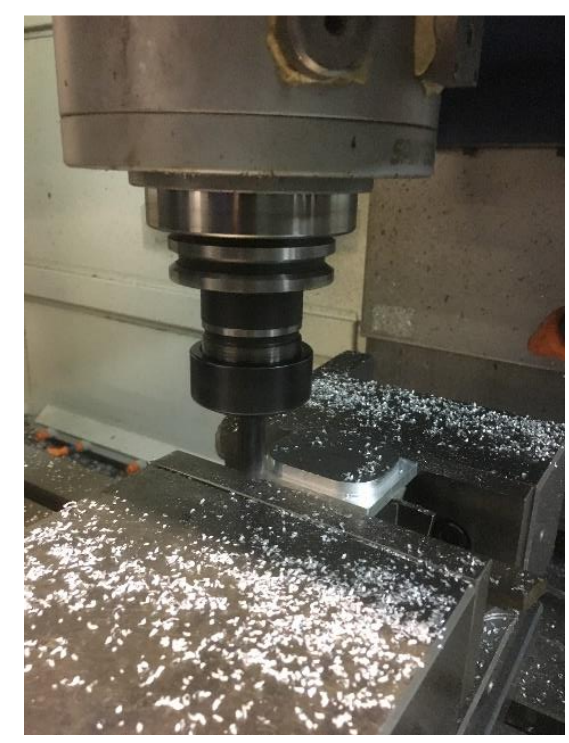

Figure 12. Milling of outer wall 


\section{Measurement of longitudinal roughness thin- walled robotic component}

Longitudinal roughness measurement on the thin-walled robotic component was performed on a Mitutoyo SJ 400 device (Figure 13). The measurement values on pages 1 and 2 at three places and on pages 3 and 4 at two places are denoted (Figure 14).

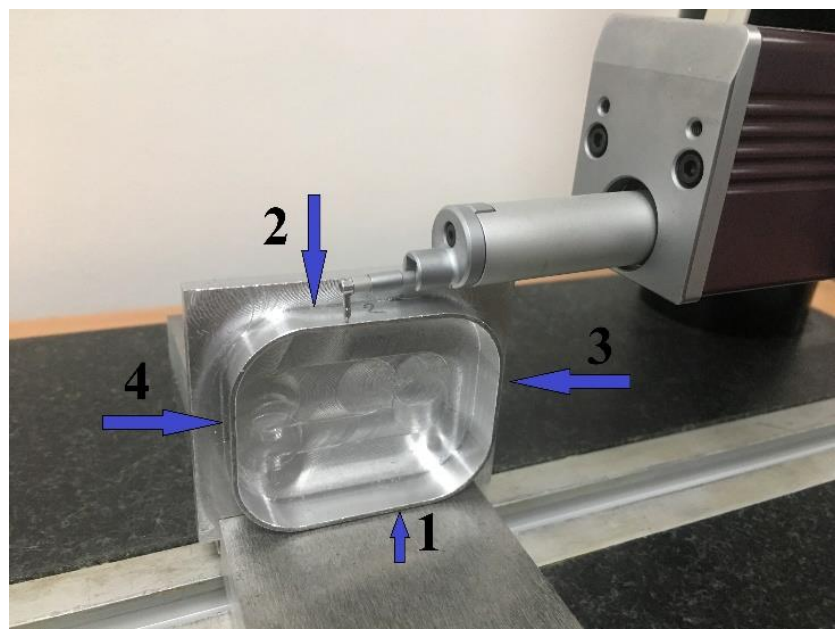

Figure 13. Measurement surface longitudinal roughness

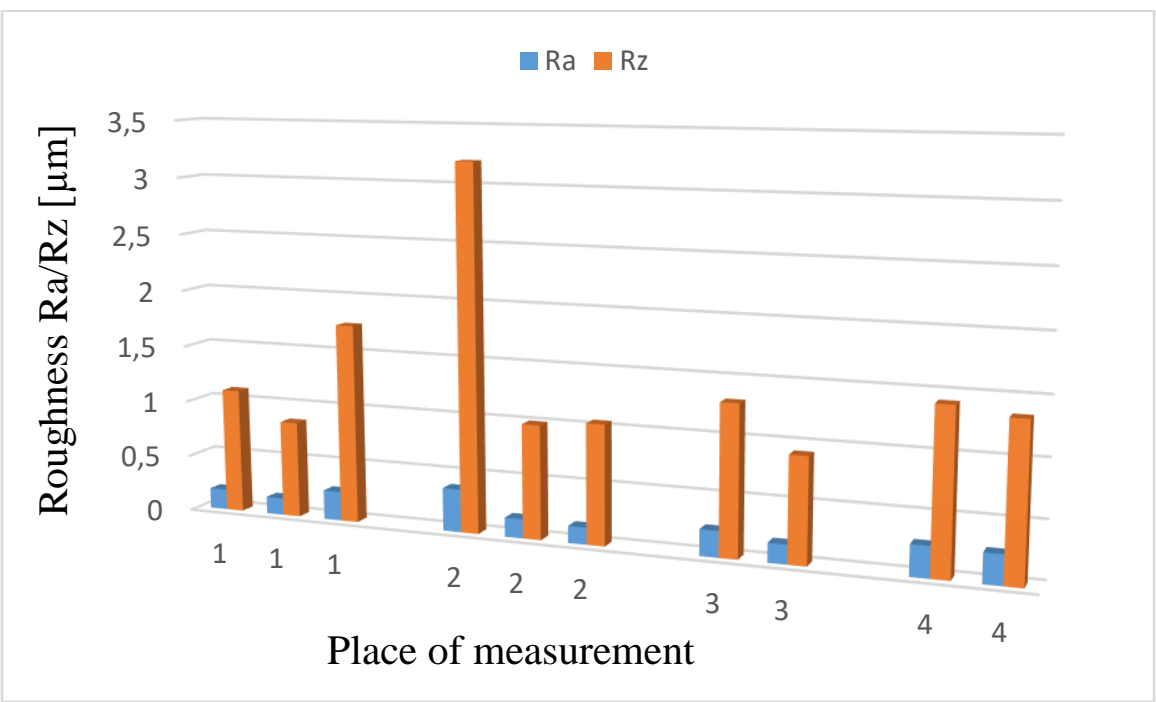

Figure 14. Values of longitudinal roughness in various places 


\section{Conclusion}

Counter-productive, risky and positive voices for Industry 4 are concerned with the role of the work of a human being by robots, which will lead to an increase in the share of capital in revenue, and on the contrary, a decline in the share of labor, at the expense of the workers. In Europe, there is a skilled workforce in the industry and, more over, there has been a population decline (for example, it is estimated that $20 \%$ in Germany will reduce the number of working-age workers by $20 \%$ compared to the present) by 2030, is more welcome. The decisive factor in the success of companies will be workers' talent rather than capital. Current initiatives in the development of digital production tools include improving user experience, so information was presented in tasks that enable users to better and more quickly respond. Steps have been taken to provide a direct link to workshop hardware, such as PLCs, control devices, computer numerically controlled (CNC machines), and more.

The Manual Guide is one of the tools leading to the digitization of manufacturing technologies. The surface quality values obtained on each side of the thin-walled robotic component are demonstrated. On the label side, 1 maximum value $\mathrm{Ra}=0,26$ $\mu \mathrm{m} / \mathrm{Rz}=1,75 \mu \mathrm{m}$, on page 2 maximum value $\mathrm{Ra}=0,38 \mu \mathrm{m} / \mathrm{Rz}=3,2 \mu \mathrm{m}$, on page 3 maximum value $\mathrm{Ra}=0,23 \mu \mathrm{m} / \mathrm{Rz}=1.31 \mu \mathrm{m}$, on page 4 maximum value $\mathrm{Ra}=$ $0.27 \mu \mathrm{m} / \mathrm{Rz}=1.42 \mu \mathrm{m}$. The lowest mean $\mathrm{Ra}=0.19666 \mu \mathrm{m}$ was achieved on page 1 and the maximum $\mathrm{Ra}=0.265 \mu \mathrm{m}$ was reached on page 4 , which can be explained by theory, the longer thin-walled area better suppresses the impact of the cutting edges of the tool to reach lower values roughness.

\section{Acknowledgements}

This work is a part of research project VEGA 1/0045/18, VEGA 1/0492/16, VEGA $1 / 0403 / 18$

\section{References}

.[1] Liptai, P., et al.: Check measurements of magnetic flux density: Equipment design and the determination of the confidence interval for EFA 300 measuring devices, Meas. J. Int. Meas. Confed. 111 (2017), p. 51-59.

[2] Murčinková, Z., et al.: Research and analysis of stress distribution in multilayers of coated tools, Int. J. Mater. Res. 108 (2017), p. 495-506.

[3] Stanova, E., et al.: Computer modelling of wire strands and ropes Part I: Theory and computer implementation, Adv. Eng. Softw. 42 (2011), p. 305315.

[4] Hosovsky, A., et al.: Preliminary investigation of static and dynamic hysteresis of DMSP-5 fluidic muscle, MM Sci. J. (2018).

[5] Olejárová, ك̌s., et al.: Measurements and evaluation of measurements of vibrations in steel milling process, Measurement. 106 (2017), p. 18-25. 
[6] Knapčikova, L., et al.: Material recycling of some automobile plastics waste, Przem. Chem. 95 (2016), p. 1716-1720.

[7] Fedorko, G., et al.: Analysis of Force Ratios in Conveyor Belt of Classic Belt Conveyor, Procedia Eng. 48 (2012), p. 123-128.

[8] Number, C., et al.: Date, FP7 Project “ ENergy Efficient Process pLANing system," (2012), p. 25 - 31.

[9] Lehocka, D., et al.: Comparison of the influence of acoustically enhanced pulsating water jet on selected surface integrity characteristics of CW004A copper and CW614N brass, Measurement. 110 (2017), p. 230-238.

[10] Duplák, J., et al.: Evaluation of T-vc dependence for the most commonly used cutting tools, Key Eng. Mater. 663 (n.d.) p. 278-285.

[11] Roblek, V., et al.: Complex View of Industry 4.0, SAGE Open. 6 (2016).

[12] Ai-xia, C., Jiang-bo, C.: Research on Intelligent CNC Turret Punch Press Process Programming System, 122 (2017), p. 228-232.

[13] Cep, R., et al.: Ceramic cutting tool tests with interrupted cut simulator, in: P. of I.C. on I.T. Praha (Ed.), IN-TECH 2010, p. 144-148.

[14] Wu, Y.: No TitleControl Module of Laser Metal Deposition Shaping System, Key Eng. Mater. 480_481 (2011), p. 644-649. 